\title{
EXPERIMENTAL VALIDATION OF A COMPUTATIONAL PROGRAM FOR SIMULATING HYBRID SOLAR AND GAS WATER HEATING SYSTEMS
}

\author{
J. M. S. Lafay, \\ and A. Krenzinger ${ }^{\mathrm{b}}$ \\ ${ }^{\text {a }}$ Universidade Tecnológica Federal do Paraná \\ Campus Pato Branco \\ Coordenação de Eletromecânica \\ Bairro Fraron \\ CEP. 85501-970, Pato Branco, Paraná, Brasil \\ jean@pb.cefetpr.br \\ ${ }^{\mathrm{b}}$ Universidade Federal do Rio Grande do Sul \\ Departamento de Engenharia Mecânica \\ CEP 900050-170, Porto Alegre,Rio Grande do Sul, Brasil.
}

\begin{abstract}
This work presents the methodology and results of the validation of a computer program for the simulation of water heating systems combining solar energy and gas. Two experimental systems, named series and parallel, were assembled. These systems have the same components, differing on how they are connected. All the components were individually characterized and their parameters determined. Simulations of the behavior of the thermal tank, gas heater and solar collector were performed and confronted to experimental data. The results show that the simulation program "AQUESOLGAS" can accurately describe the behavior of water heating systems with solar energy and gas.
\end{abstract}

Keywords: Solar energy, Water Heating, Simulation.

\section{NOMENCLATURE}

$\mathrm{U} \quad$ Overall loss coefficient, $\mathrm{W} /{ }^{\circ} \mathrm{C}$

E Internal energy, $\mathrm{kJ}$

$\mathrm{T} \quad$ Temperature, ${ }^{\circ} \mathrm{C}$

$\mathrm{t}$ Time, $\mathrm{h}$

\section{INTRODUCTION}

The number of installed residential and industrial solar water heating systems all around the world has been growing over the years. Nevertheless, it can also be observed that incentive and support by governmental institutions must be provided for a more intense dissemination of such technologies. The main item that holds back the expansion of this market is the initial cost of solar water heating systems. In spite of the long life cycle (about 20 years) and the rather short payback time, the economical reality of most of the Brazilian families keeps them away from the benefits of such systems.

A hybrid water heating system combining solar energy and natural gas is proposed by the Solar Energy Laboratory of the Federal University of Rio Grande do Sul, aiming the reduction of the installation costs of solar water heating systems without compromising the quality. This system proposes lowering the initial cost by undersizing the solar fraction (i.e. reducing the number of solar collectors) and increasing the operational costs (gas consumption). It must be stressed that the cost of the natural gas is considerably lower than the equivalent electricity. Furthermore, in a future moment the owner can add more solar collectors to the system, diminishing the operational costs.
A simulation software, called AQUESOLGAS and sponsored by UFRGS, PETROBRÁS and FINEP, was developed to serve as a tool both for a better understanding of the behavior of such systems as well as for helping the engineer when sizing an installation. Two solar-gas water heating systems were assembled. These were monitored by a data acquisition system controlled by a computer. The simulation software, after validated with experimental data, will be used to size systems leaning to the maximum efficiency.

\section{DESCRIPTION OF THE EXPERIMENTAL SYSTEMS}

Two hybrid solar-gas water heating systems, named parallel and series, were assembled. Both were constituted by identical components, differing on the interconnection scheme. Each system contains two flat plane solar collectors (connected in parallel between each other), a thermally insulated stainless steel tank, an instant gas heater, a pump and a thermostat. Components are interconnected with copper piping insulated with polyethylene foam tubes. A fiberglass cold water supply tank is shared by both systems. Each system presents two water circuits. In the solar section the water flows through the solar collectors by thermosiphon. The gas heater circuit (auxiliary heat source) is provided with a pump. The thermostat actuates the pump (and thus the gas heater) whenever the temperature of the water near its sensor (installed at $73 \mathrm{~cm}$ from the bottom of the tank) is below $43{ }^{\circ} \mathrm{C}$. The pump is deactivated when this temperature reaches $44^{\circ} \mathrm{C}$. 
Figure 1 shows the differences between the systems. In the parallel configuration both the inlets of the solar collector and the gas heater are connected to the bottom of the tank, while their outlets are connected to the top of the tank. In the series configuration the inlet of the solar collector is also connected to the bottom of the tank but returns to the tank at half height. The gas heater inlet is connected to the tank at half height while its outlet connects to the top of tank.

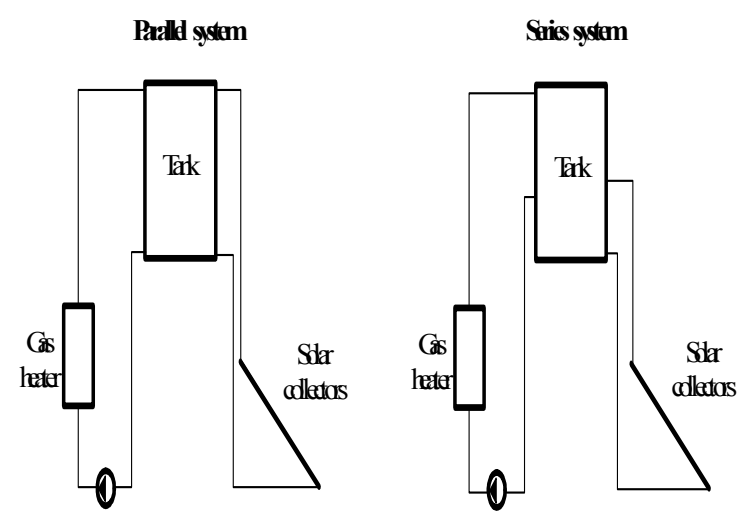

Figure 1. Schematic diagram showing the hydraulic connections of the parallel and series systems.

Temperature sensors were installed to measure the temperatures of the water and ambient air. Solar irradiance is sensed by a photovoltaic pyranometer (Zanesco, 1991). The sensors signals are collected by an automated data acquisition system controlled by a computer.

The characterization of the system components was made according to ABNT standards $(1988,1998)$ and the results were published in Lafay et al (2003). Gutierrez et al (1974) and Shariah (1997) simulated the influence of the time of day and amount of the consumption on water heating systems with solar energy and an auxiliary energy source (electric heater). Very little is known, at the present time, about the influence of the consumption on the proposed systems. Results of preliminary tests varying the consumption schedule are presented in Lafay et al (2004).

The objective of the experimental assembly was to obtain reliable parameters for a successful simulation of the systems under study and generate experimental data to be compared to the simulation results. The main parameters are the solar collectors efficiency curve, the gas heater efficiency and the overall thermal loss coefficient of the tanks.

Table 1 presents the parameters experimentally obtained for each system. Some constructive characteristics of the heating systems, including the height of the connections to the tank, are presented in Tab. 2.

The geometry data are informed to the software through the form presented in Fig. 2.
Table 1. Parameters of the experimental water heating systems.

\begin{tabular}{|c|c|c|}
\hline $\begin{array}{c}\text { Efficiency curve of } \\
\text { the solar collectors }\end{array}$ & $\begin{array}{c}\text { Parallel } \\
\text { system }\end{array}$ & $\begin{array}{c}\text { Series } \\
\text { system }\end{array}$ \\
\hline $\begin{array}{c}\text { Gas heater } \\
\text { efficiency }\end{array}$ & 0.81 & 0.81 \\
\hline Gas flow $\left(\mathrm{m}^{3} / \mathrm{h}\right)$ & 0.31 & 0.28 \\
\hline $\begin{array}{c}\text { Water flow through } \\
\text { the gas heater } \\
\left(\mathrm{m}^{3} / \mathrm{h}\right)\end{array}$ & 0.18 & 0.21 \\
\hline $\begin{array}{c}\text { Hot water } \\
\text { consumption flow } \\
\left(\mathrm{m}^{3} / \mathrm{h}\right)\end{array}$ & 0.322 & 0.325 \\
\hline $\begin{array}{c}\text { Average overall } \\
\text { thermal loss } \\
\text { coefficient of the } \\
\text { tanks }\left(\mathrm{W} /{ }^{\circ} \mathrm{C}\right)\end{array}$ & 4.2 & 4.8 \\
\hline
\end{tabular}

Table 2. Heights of the tanks connections (measured from the bottom).

\begin{tabular}{|c|c|c|}
\hline & $\begin{array}{c}\text { Parallel } \\
\text { system }\end{array}$ & $\begin{array}{c}\text { Series } \\
\text { system }\end{array}$ \\
\hline $\begin{array}{c}\text { Tank outlet to the solar } \\
\text { collectors (mm) }\end{array}$ & 80 & 80 \\
\hline $\begin{array}{c}\text { Tank inlet from the solar } \\
\text { collectors (mm) }\end{array}$ & 1100 & 540 \\
\hline $\begin{array}{c}\text { Tank outlet to the gas heater } \\
\text { (mm) }\end{array}$ & 80 & 440 \\
\hline $\begin{array}{c}\text { Tank inlet from the gas heater } \\
\text { (mm) }\end{array}$ & 1100 & 1100 \\
\hline $\begin{array}{c}\text { Tank inlet from the cold water } \\
\text { supply (mm) }\end{array}$ & 80 & 80 \\
\hline $\begin{array}{c}\text { Tank outlet of consumption hot } \\
\text { water (mm) }\end{array}$ & 950 & 950 \\
\hline Thermostat sensor height (mm) & 730 & 730 \\
\hline $\begin{array}{c}\text { Distance between collector top } \\
\text { an tank base (mm) }\end{array}$ & 400 & 400 \\
\hline
\end{tabular}

\section{SIMULATION PROGRAM}

The software employed in this work, AQUESOLGAS, was conceived as a tool for the simulation and sizing of water heating systems with solar energy and gas. It was developed in Visual Basic 5.0 at the Solar Energy Laboratory of the Federal University of Rio Grande do Sul, as part a project sponsored by FINEP and PETROBRAS. The software has a friendly interface, demanding some basic information about the installation. An important feature is the ability of simulating each component individually and saving the result to form the overall system simulation. In the case of solar energy and gas water heating systems the items are: solar collectors, thermal tank, gas heater and piping. Besides the physical data, the software considers the displacement of the layers of water inside the tank in function of the temperature and also some logic events, as the activation of the thermostat and pump. 
Meteorological data required are monthly averaged ambient temperature and solar radiation.

The software is divided in five main modules: solar collectors, thermal tank, profile, piping and geometry. Figure 2 presents the form containing the geometry data of the system to be simulated.

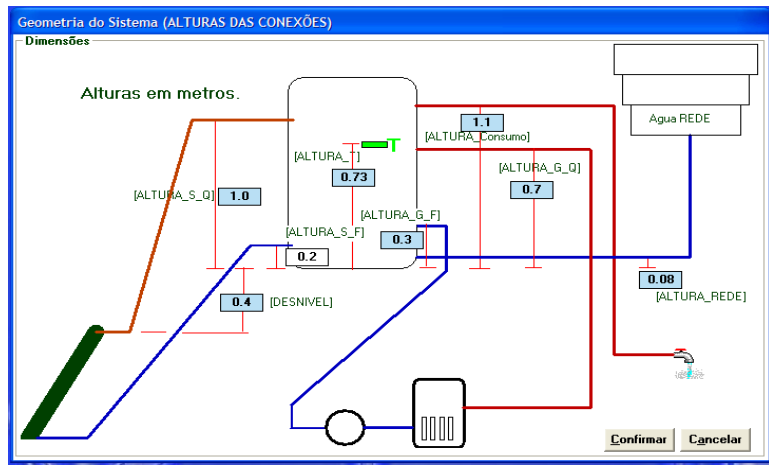

Figure 2. Form of the geometry of the system to be simulated.

The mathematical modeling adopted for each component was originated from diverse authors. For the solar collectors the classical approximation of Hottel-Bliss-Whillier, presented by Duffie and Beckman (1991), was employed. The heat exchange processes inside the thermal tank can be simulated with two-dimensional models (e.g. Olivesky et al (2003)) but the multi-nodal unidimensional calculation in sufficient in this case. The model described by Hussein (2002) was employed for the temperature distribution inside the tank. This model was adapted to allow a larger number of connections to the tank and the external gas heater.

Collector dimensional data and efficiency curve are introduced through the form presented in Fig. 3. Further information about details of the models and software structure can be found in Krenzinger et al (2003)



Figure 3. Collector dimensional data and efficiency curve form (show with data from the employed collector).

\section{METHODOLOGY OF VALIDATION OF THE SIMULATION SOFTWARE}

Each component of the water heating system was simulated with the same meteorological data of the experimental tests. All of the parameters experimental systems and the initial conditions are informed. Since both systems use identical components, measuring them simultaneously ensures that the perceived differences are due only to the diverse connection scheme and not to variations of the meteorological conditions.

The validation process began with the thermal tank. The cooling of the tank was simulated by feeding the program with a data file with zero radiation. There was no hot water consumption and the pump/gas heater was inhibited since the experimental cooling test is influenced only by the overall thermal loss coefficient of the tank.

With the thermal tank module validated, the next step was to simulate the instant gas heater. The connection heights indicated in Tab. 2 were informed, as well as the efficiency, the gas flow, the water flow, the gas higher heating value and the thermostat set point $\left(43^{\circ} \mathrm{C}\right)$.

The dimensions and physical properties of the solar collector can be informed in the form presented in Fig. 3. Alternatively the collector efficiency curve, if available, can be informed instead. The second option was chosen in this work, because it has already been experimentally determined. Once this form is complete, the user is prompted to inform the initial temperatures of the layers of the experimental model to be simulated, as well as the meteorological data corresponding to the period of the test.

\section{RESULTS}

The profile of the temperature of the water layers inside the tank is promoted by the way the heat is transferred through the water, the tank wall, the insulation, the external coating and the ambient temperature. The internal convection and heat diffusivity of the water also have their influence on the temperature profile. The overall loss coefficient of the tank is determined from experimental temperature data. The wind speed was not considered in the calculation because there was no anemometer in the experiment. Nevertheless its effect can be observed from the small fluctuations of the loss coefficient value. This variation depends on the period $(\Delta t)$ considered for the calculation of Eq.(1).

$$
U=\frac{\Delta E_{i}}{\left(T_{a}-T_{m}\right) \cdot \Delta t}
$$

where $\Delta \mathrm{Ei}$ is the variation of the internal energy of the tank over the considered period $(\mathrm{kJ})$, Ta is the ambient temperature $\left({ }^{\circ} \mathrm{C}\right), \quad \mathrm{Tm}$ is the average temperature of the water inside the tank $\left({ }^{\circ} \mathrm{C}\right)$ and $\Delta \mathrm{t}$ is the considered period $(\mathrm{t})$. 
Several cooling tests of the tanks, with different initial temperature conditions, were performed on April 1st, 5th and 8th. The simulation of these tests agreed with the experimental results. Figures 4 and 5 present the experimental and simulated temperature profiles of the water inside the parallel system tank over a period of 22 hours.

The results of the simulations performed with the calculated overall loss coefficient were, as expected, closer to the experimental results. Since the software aims for a friendly interface, only the parameters presented in Table 1 were employed in the simulations performed in this work, as most of the users have no access to more accurate (calculated) parameters.

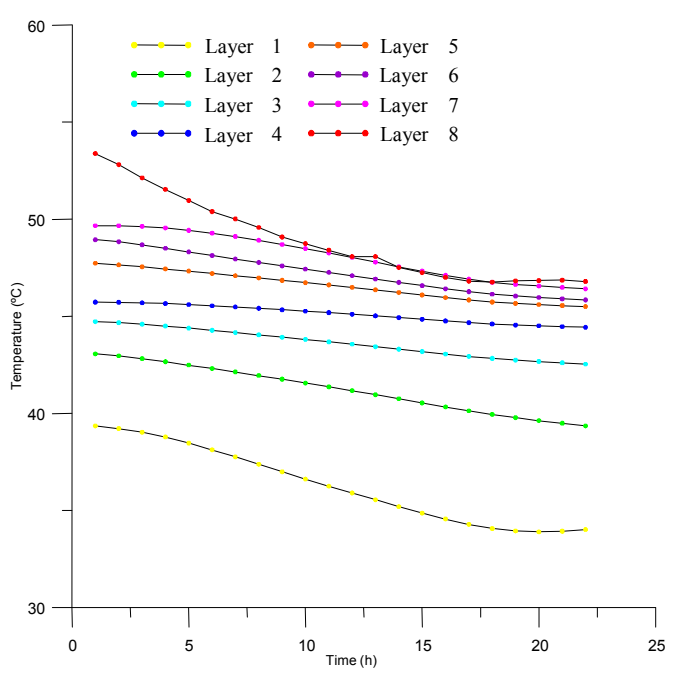

Figure 4. Experimental temperature profiles of the water layers inside the tank (parallel system) on 04/01/2004.

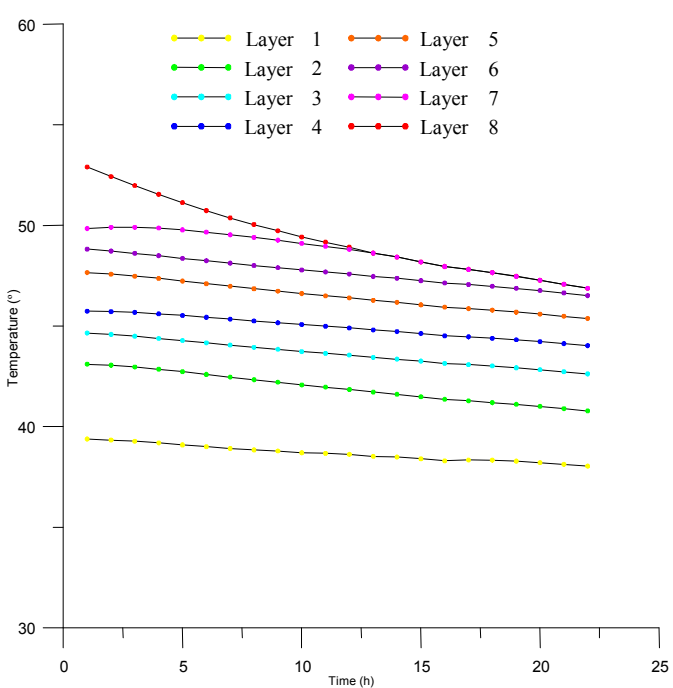

Figure 5. Simulated temperature profiles of the water layers inside the tank (parallel system) on 04/01/2004.
As can be observed in the figures above, all of the simulated temperatures layers are similar to the experiment, with the exception of layer 1. This difference can be explained from the fact that the program splits the overall thermal losses of the tank into lateral, top and bottom losses, considering the same insulation thickness for all regions. The experimental results suggest that this may not be true for the employed tank.

Figures 6 and 7 present the experimental and simulated temperature profiles of the water inside the parallel system tank over a period of 60 hours.



Figure 6. Experimental temperature profiles of the water layers inside the tank (parallel system) on 04/05/2004.

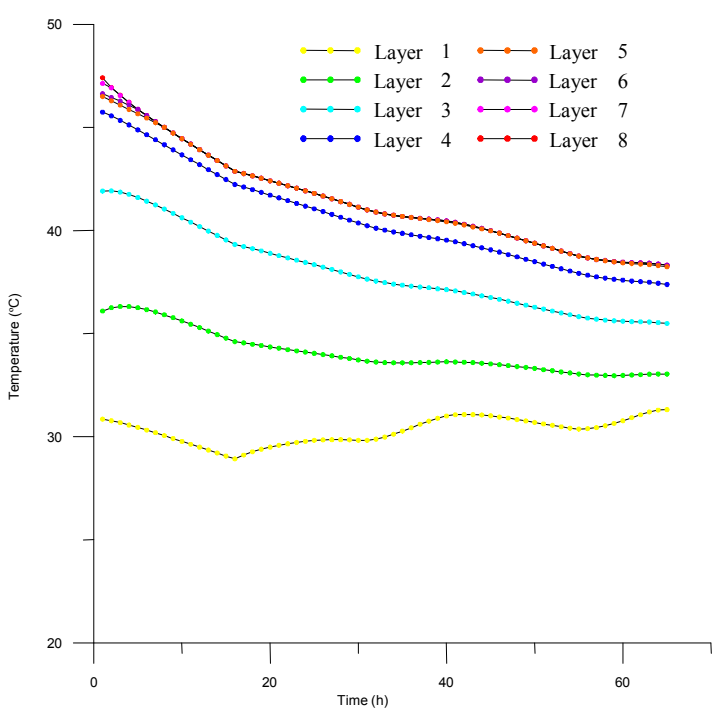

Figure 7. Simulated temperature profiles of the water layers inside the tank (parallel system) on 04/05/2004 
Figures 8 and 9 present the experimental and simulated temperature profiles of the water inside the parallel system tank over a period of 80 hours.



Figure 8. Experimental temperature profiles of the water layers inside the tank (parallel system) on 04/08/2004.



Figure 9. Simulated temperature profiles of the water layers inside the tank (parallel system) on 04/08/2004.

Figures 10 to 13 represent the experimental and simulated results with automated gas heater activated only. The behavior of the experimental and simulated temperatures of the water layers inside the parallel system tank showed a good agreement, as can be seen in Figs. 10 and 11. The gas heater first started around the same time (40th hour) for both models. The water temperature in layer 8 presents more peaks in the simulated model. Nevertheless, the amplitude of these peaks is lower than those observed in the experiment, resulting in an equivalent average temperature in this layer for both experimental and simulated models.



Figure 10. Experimental temperature profiles of the water layers inside the tank (parallel system) on $04 / 17 / 2004$ with the automated gas heater activated.

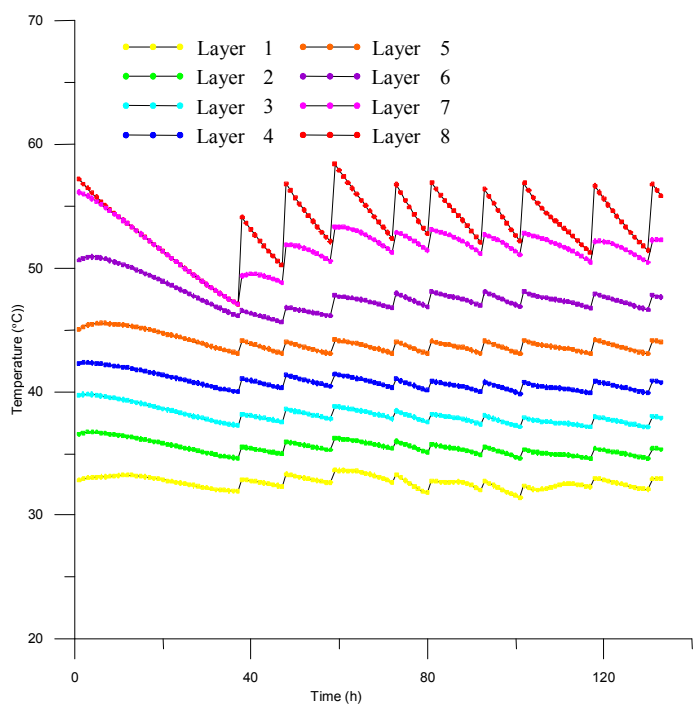

Figure 11. Simulated temperature profiles of the water layers inside the tank (parallel system) on $04 / 17 / 2004$ with the automated gas heater activated.

Figures 12 and 13 show the experimental and simulated temperature profiles for the series system. Again, a good agreement between both models, concerning temperature values and number of times the gas heater was activated, can be observed. It can be noticed also that layers 1,2 and 3 are hardly influenced by the gas heater, since in this configuration they are located below the connection from the heater. 


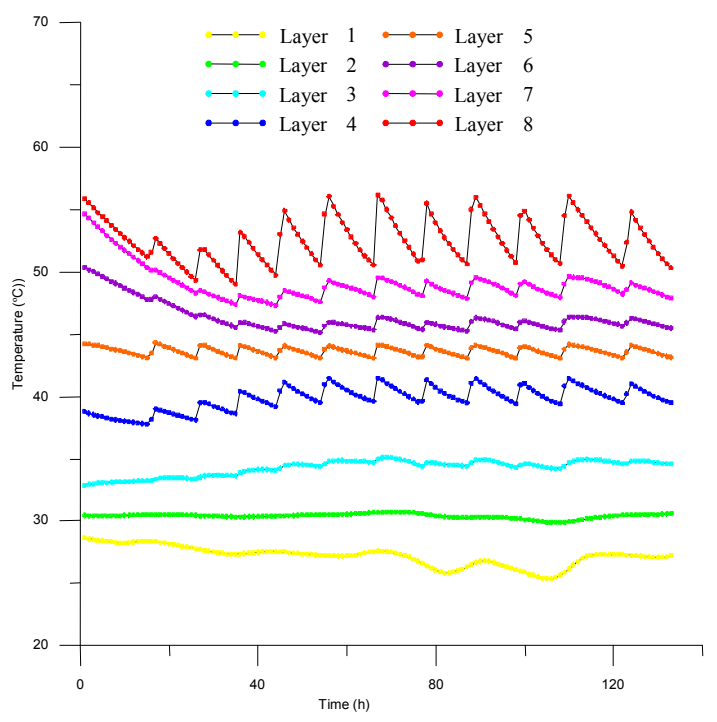

Figure 12. Experimental temperature profiles of the water layers inside the tank (series system) on 04/17/2004 with the automated gas heater activated.

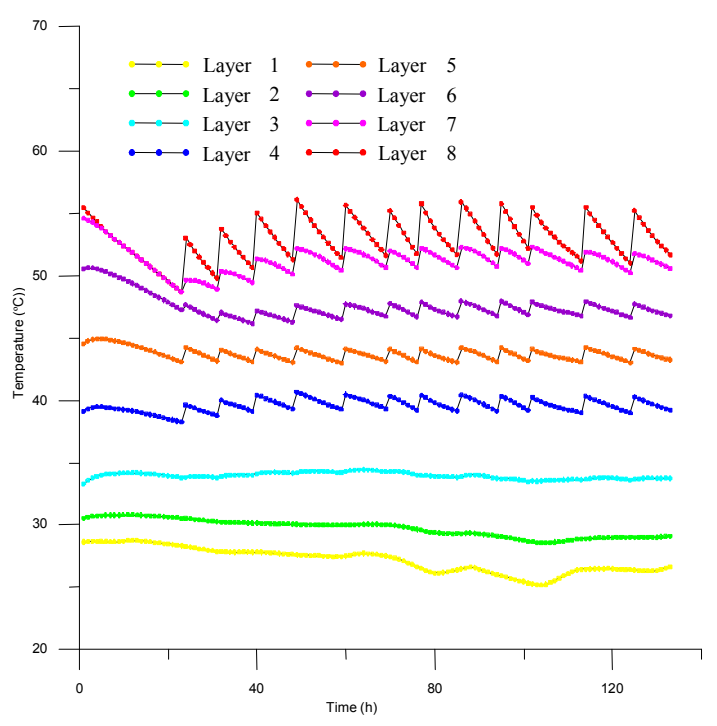

Figure 13. Simulated temperature profiles of the water layers inside the tank (series system) on 04/17/2004 with the automated gas heater activated.

Figures 14 to 17 represent the experimental and simulated results with solar energy only. Both experimental systems were tested in the same day, so they were submitted to the same external conditions. The initial conditions were similar and a stronger stratification was soon developed in the parallel system tank, which was observed to remain to the end of the test.

Once again the temperatures of the layers in the experimental and simulated models presented a good agreement, with the exception of layer 8 . In the experimental parallel system (Fig. 14) the layers temperatures tend to converge just before the peak of temperature. The water that flows through the solar collector comes from the bottom of the tank, where the stratification is strong and the temperature is low.

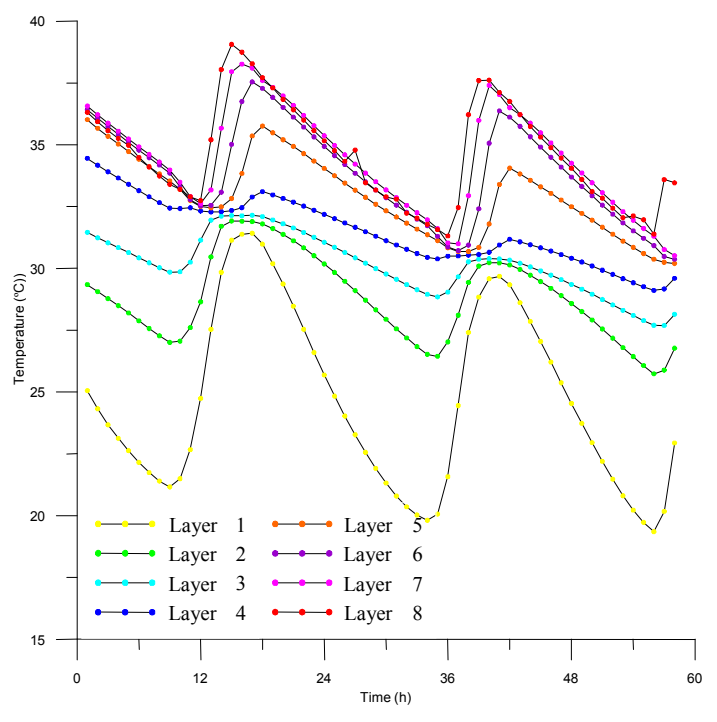

Figure 14. Experimental temperature profiles of the water layers inside the tank (parallel system) on 09/13/2003 with solar energy only.

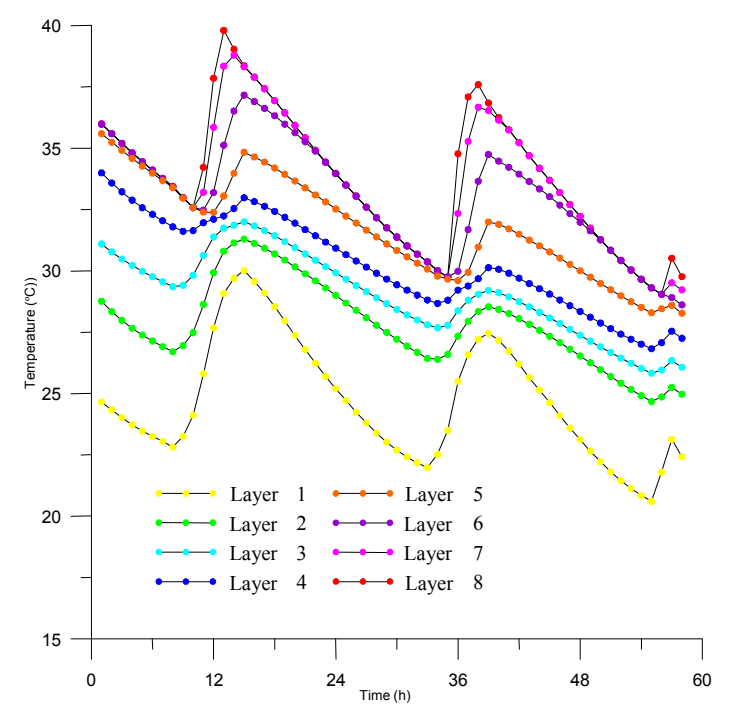

Figure 15. Simulated temperature profiles of the water layers inside the tank (parallel system) on 09/13/2003 with solar energy only.

Due to the height of the return pipe from the solar collector to the tank, the low irradiance of the first hours of the day makes the higher layers to eventually cool. In this simulation, Hussein model (2002) employed in the program has been already modified by Krenzinger (2003). 


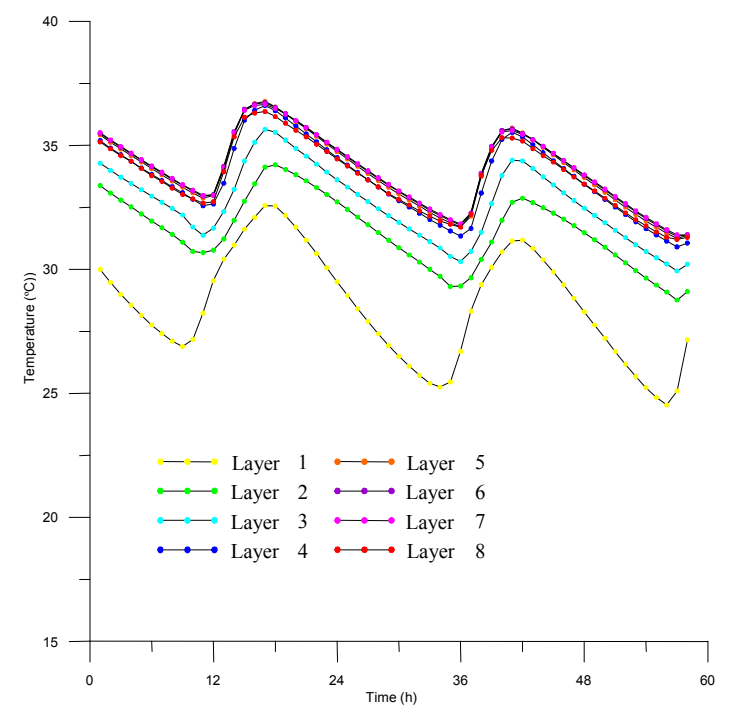

Figure 16. Experimental temperature profiles of the water layers inside the tank (series system) on 09/13/2003 with solar energy only.

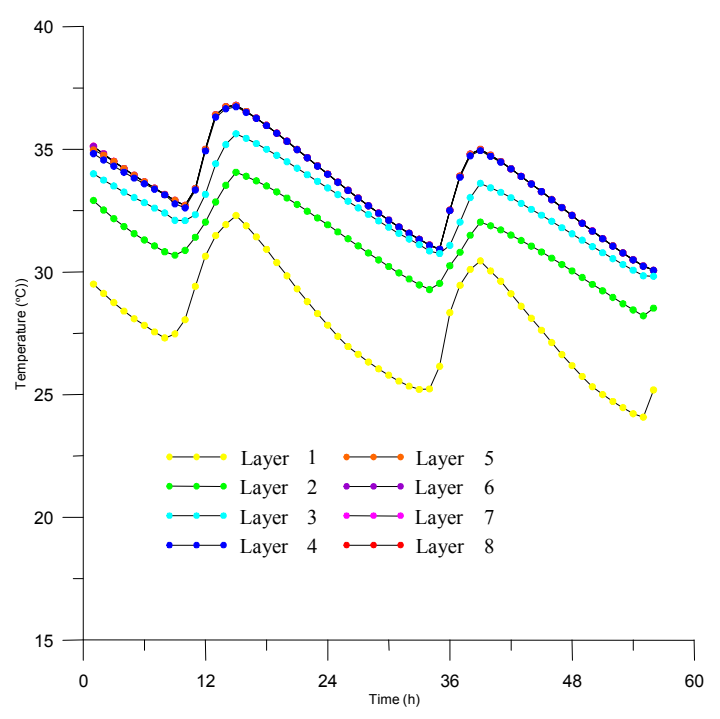

Figure 17. Simulated temperature profiles of the water layers inside the tank (series system) on $09 / 13 / 2003$ with solar energy only.

\section{CONCLUSIONS}

The parallel and series experimental systems provided reliable data about the behavior of the temperature profiles inside the tanks. The analysis of these data and characterization of the system components allowed the determination of the inherent parameters of the experimental systems.

The simulation program was tested using meteorological measured data instead of computer synthesized data (witch is normally supplied by the software) in order to produce significant comparisons. In the same way, actual initial conditions were inputted.
The resulting simulations reveal the individual thermal behavior of the tanks, the gas heaters and the solar collectors, as well as their assembled thermal behaviour. These results were very close to their corresponding experimental data and this fact validate the program for future applications.

The performed simulations verified the behavior of the thermal tank, the gas heaters and the solar collectors. The results from the simulations were very close to the corresponding experimental results.

\section{ACKNOWLEDGEMENTS}

This work was supported by Conselho Nacional de Desenvolvimento Científico e Tecnológico CNPq, PETROBRÁS and FINEP.

\section{REFERENCES}

Associação Brasileira de Normas Técnicas, 1988. "Coletores Solares Planos para Líquidos Determinação do Rendimento Térmico (NBR10184)", Rio de Janeiro, Brazil.

Associação Brasileira de Normas Técnicas, 1998. "Aquecedor de Água a Gás Tipo Instantâneo Requisitos e Métodos de Ensaio (NBR8130)", Rio de Janeiro, Brazil.

Duffie, J.A., Beckman, W.A., 1991. "Solar Engineering of Thermal Processes", Wiley Interscience Publication.

Gutierrez, G., Hincapie, F., Duffie, A., Beckman, W.A., 1974. "Simulation of forced circulation water heaters; effects of auxiliary energy supply, load type and storage capacity", Solar Energy Vol. 15, pp 287-298.

Hussein, H.M.S., "Transient Investigation of a two phase closed thermosyphon flat plate solar water heater", Energy Conversion and Management 43, (2002), 2479-2492.

Krenzinger, A., Siqueira, A.M.O., Oliveski, R.C., 2003. "Aquesolgas", 17th International Congress of Mechanical Engineering, São Paulo, Brasil

Lafay, J.M., Krenzinger, A., Prieb, C., 2003. "Experimental Results For Hybrid Solar \& Gas Water Heating Systems", 17th International Congress of Mechanical Engineering, São Paulo, Brazil.

Lafay, J.M., Krenzinger, A., Prieb, C., 2004. "Influência do horário de consumo de água quente no rendimento de sistemas de aquecimento de água com energia solar e gás", III Congresso Nacional de Engenharia Mecânica, Belém, Brazil.

Oliveski, R.C., Krenzinger, A., Vielmo, H.A., 2003. "Cooling of Cylindrical Vertical Tanks Submited to Natural Internal Convection", International Journal of Heat and Mass Transfer, Elsevier Science Ltd., v. 46, pp2015-2026, 2003.

Shariah, A.M., Löf, G.O.G., 1997. "Effects of auxiliary heater on annual performance of thermosyphon solar water heather simulated under 
variable operating conditions", Solar Energy Vol. 60, $\mathrm{N}^{\circ}$ 2, pp119-126.

Zanesco, I., 1991. “Análise e Construção de um Piranômetro Fotovoltaico", PROMEC, Universidade Federal do Rio Grande do Sul, Porto Alegre, Brazil.

Viskanta, R., 1995, Convective Heat Transfer in Consolidated Porous Media: A Perspective, in: Symposium on Thermal Science and Engineering in Honor of Chancellor Chang-Lin Tien, University of California, Berkeley, pp. 43-50. 